ADC

\title{
A paediatric telecardiology service for district hospitals in south-east England: an observational study
}

R Dowie, H Mistry, M Rigby, et al.

Arch Dis Child 2009 94: 273-277 originally published online September 11, 2008

doi: 10.1136/adc.2008.138495

Updated information and services can be found at:

http://adc.bmj.com/content/94/4/273.full.html

Topic collections Articles on similar topics can be found in the following collections

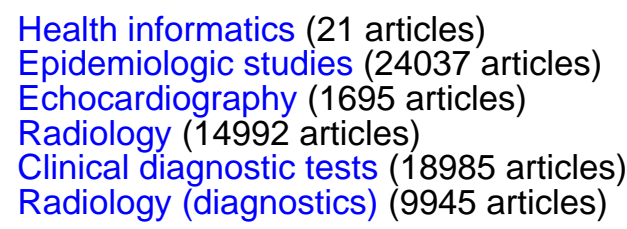

Notes

To order reprints of this article go to:

http://adc.bmj.com/cgi/reprintform

To subscribe to Archives of Disease in Childhood go to:

http://adc.bmj.com/subscriptions 


\title{
A paediatric telecardiology service for district hospitals in south-east England: an observational study
}

\author{
R Dowie, ${ }^{1} \mathrm{H}$ Mistry, ${ }^{1} \mathrm{M}$ Rigby, ${ }^{2} \mathrm{~T}$ A Young, ${ }^{3} \mathrm{G}$ Weatherburn, ${ }^{4} \mathrm{G}$ Rowlinson, ${ }^{2}$ \\ R C G Franklin²
}

${ }^{1}$ Health Economics Research Group, Brunel University, Uxbridge, UK; ${ }^{2}$ Royal Brompton Hospital, Royal Brompton and Harefield NHS Trust, London, UK; ${ }^{3}$ Health Economics and Decision Science, School of Health and Related Research, University of Sheffield, Sheffield, UK; ${ }^{4}$ Research Centre for Society and Health, Buckinghamshire New University, Chalfont St Giles, UK

Correspondence to: Robin Dowie, Health Economics Research Group, Brunel University, Uxbridge, Middlesex UB8 3PH, UK; robin.dowie@brunel.ac.uk

Accepted 19 August 2008 Published Online First 11 September 2008

\begin{abstract}
Objectives: To compare caseloads of new patients assessed by paediatric cardiologists face-to-face or during teleconferences, and assess NHS costs for the alternative referral arrangements.

Design: Prospective cohort study over 15 months.

Setting: Four district hospitals in south-east England and a London paediatric cardiology centre.

Patients: Babies and children.

Intervention: A telecardiology service introduced alongside outreach clinics.
\end{abstract}

Measurements: Clinical outcomes and mean NHS costs per patient.

Results: 266 new patients were studied: 75 had teleconsultations (19 of 42 newborns and 56 of 224 infants and children). Teleconsultation patients generally were younger (49\% being under 1 year compared with $32 \%$ seen personally $(p=0.025))$ and their symptoms were not as severe. A cardiac intervention was undertaken immediately or planned for five telemedicine patients (7\%) and 30 conventional patients (16\%). However, similar proportions of patients were discharged after being assessed (32\% telemedicine and 39\% conventional). During scheduled teleconferences the mean duration of time per patient in sessions involving real-time echocardiography was $14.4 \mathrm{~min}$, and $8.5 \mathrm{~min}$ in sessions where pre-recorded videos were transmitted. Mean cost comparisons for telemedicine and face-to-face patients over 14-day and 6-month follow-up showed the telecardiology service to be cost neutral for the three hospitals with infrequently-held outreach clinics ( $£ 1519$ vs £1724 respectively after 14 days).

Conclusion: Paediatric cardiology centres with small cadres of specialists are under pressure to cope with ever-expanding caseloads of new patients with suspected anomalies. Innovative use of telecardiology alongside conventional outreach services should suitably, and economically, enhance access to these specialists.

The clinical specialty of paediatric cardiology in the United Kingdom (UK) is concentrated in 15 centres that support nearly 200 district general hospitals $(\mathrm{DGH})$. As there are fewer than 80 paediatric cardiology consultants, it is proving increasingly difficult to provide a timely and efficient service to all patients requiring specialist input. Urgent cases detected in the DGHs are transferred rapidly to the specialist centres, with critically ill babies frequently requiring admission to intensive care units. Neonates with moderately severe clinical problems may also be transferred for diagnostic clarification or advice on management, while non-urgent cases are assessed in daily outpatient clinics. In addition, paediatric cardiologists hold outreach clinics in
DGHs from every week to 6-monthly, at anywhere up to 30 different sites per centre. ${ }^{12}$

Outreach caseloads typically include infants and children with congenital heart disease (CHD) under long-term review or who are being monitored prior to, and after, treatment. The majority of new cases, however, are children whom the district paediatricians wish to screen for a possible heart anomaly in the setting of an asymptomatic murmur. ${ }^{3}$ As the incidence of $\mathrm{CHD}$ is just under $1 \%$ and that of innocent murmurs is over $50 \%$ at some point during childhood, the vast majority of these children have normal hearts. Best practice dictates that a strong suspicion of $\mathrm{CHD}$ requires assessment with an echocardiogram. Unfortunately, it is increasingly difficult for paediatricians not to refer asymptomatic patients with clear-cut innocent murmurs. Parental expectations, based on media and internet sourced information, have created an environment in which often only an echocardiogram will provide sufficient reassurance of normality. Triaging asymptomatic children with murmurs using echocardiography is demanding of time and resources, ${ }^{3}$ and waiting times for new non-urgent appointments in outreach clinics are often many weeks. ${ }^{4}$

Paediatric cardiology lends itself to telemedicine. Almost all forms of CHD can be diagnosed from a clinical examination, including auscultation sounds using a stethoscope and from echocardiographic and Doppler-derived images. The outputs of these modalities are suitable for electronic transmission. ${ }^{56}$ However, few applications in paediatric cardiology involving networks of hospitals have been reported. Canadian networks accept referrals of neonates and children. ${ }^{7-9}$ A neonatal service in Northern Ireland links the paediatric cardiology centre in Belfast with four DGHs, ${ }^{10-12}$ while a network in Scotland extends across 10 or more sites with the tertiary centre in Glasgow as the hub for neonatal referrals. ${ }^{13}$

In 2001, the paediatric cardiology centre at the Royal Brompton Hospital (RBH) in London, with telecardiology links in Greece and Portugal, ${ }^{14} 15$ introduced a telemedicine service in four DGHs in south-east England for use in neonatal units, paediatric departments and obstetric departments. Within each hospital, the clinicians and managers decided on the precise role for this new service. The Department of Health funded an independent study to observe how the telemedicine service was adopted in the hospitals, and to compare the costs and outcomes of new patients seen by specialists using telemedicine or in face-to-face consultations. A published economic analysis covering all three applications of the service (fetal, neonatal and paediatric) showed that the network, 
operating as an isolated telecardiology service, was cost neutral when compared with conventional referral practice once patients were followed up over 6 months. ${ }^{16}$

This paper concentrates on the neonatal and paediatric applications with two objectives:

- to compare the caseloads of patients who had teleconsultations with the caseloads of patients who had face-to-face consultations, while reviewing the operation of the service;

- to assess the relative costliness to the National Health Service (NHS) of the telecardiology service for neonatal and paediatric patients compared with conventional referral arrangements.

\section{METHODS}

The telecardiology service was introduced into Basildon, Colchester, Gillingham and Southend DGHs, between 35 and 65 miles from central London. $\mathrm{RBH}$ paediatric cardiologists held outreach clinics monthly in Gillingham, and 3- or 4-monthly in the other towns. Gillingham had a level 3 neonatal intensive care unit, while level 2 care was provided in the other towns. Babies and children with heart problems were referred to $\mathrm{RBH}$ or to two other London centres, and those judged non-urgent were referred to $\mathrm{RBH}$ outreach clinics.

The telemedicine equipment package for each DGH included a Tandberg video conferencing system for use with six integrated services digital network (ISDN) lines, additional monitors, a video recorder, an object camera visualiser, and, in three hospitals, an electronic stethoscope sender. The telecardiology service complemented existing outreach services, which continued unchanged. Patients were considered for teleconsultations at the discretion of the district paediatricians. Urgent consultations were arranged by telephone and held within a few hours, while teleconferences with booked appointments were scheduled routinely.

The economic evaluation was designed as a randomised study. However, because of the uncertainty about how the DGH clinicians would adopt the technical innovation, the hospitals were randomised rather than individual patients. Basildon and Gillingham were the intervention sites, but the uptake of the service during the first 6 months was slower than anticipated. So, to provide sufficient cases for the cost analysis, Colchester and Southend began using their telemedicine equipment thereafter. Multi-centre and local research ethics committees approved the project.

Babies and children, who were newly assessed by paediatric cardiologists between May 2001 and September 2002, were identified by project facilitators in the four DGHs. Clinical events were identified from hospital records for costing purposes and demographic information and outcomes were extracted from case notes. The teleconferences were audited.

For the analysis from the NHS perspective, costs for resource items were obtained from the hospital finance and pharmacy departments, NHS ambulance trusts, and a hospital with a retrieval team for neonatal transfers. Medical staff time was costed. The methods for handling these data and attributing unit costs to resource items have been described elsewhere. ${ }^{16}$ Originally, the costs, including overheads, applied to the 200102 financial year, but for this paper they have been inflated to 2005-06 prices using the Pay and Prices Index ${ }^{17}$ (table 1). Bootstrapped ${ }^{18}$ mean costs per patient for the telemedicine and conventional referral services were calculated for the initial consultation day, 14 days inclusive of the initial consultation, and a maximum period of 6 months. The short-term period covered emergency events (ambulance transfers, surgical or transcatheter procedures), but to minimise the weighting effect of costly post-operative care on the mean costs, 14 days was selected. A 6-month period had been used in an evaluation of virtual outreach referral services in two English hospitals. ${ }^{19}$

The survey datasets were analysed using SPSS v 13.0 (SPSS, Chicago, IL) and Stata v 9.2 (StataCorp. College Station, TX); $\mathrm{t}$ tests, and $\chi^{2}$ tests were used (two-sided). A p-value of $\leqslant 0.05$ was considered to be statistically significant.

\section{RESULTS}

A total of 266 patients were audited: 42 newborns and 224 infants and children. Nineteen (45\%) newborns and $56(25 \%)$ children had teleconsultations.

\section{Demographic and clinical characteristics (table 2)}

Teleconsultation patients were younger overall ( $p=0.025) ; 49 \%$ were under 1 year compared with $32 \%$ of the face-to-face patients. Teleconsultation patients were less likely to have critical or moderate to severe symptoms ( $8 \%$ vs $22 \%$; p $=0.005$ ) and were therefore referred less often for urgent or inpatient investigation $(p<0.001)$.

Table 3 identifies the cardiac diagnoses for 35 children for whom an intervention was planned or undertaken immediately; 15 were newborns, and 14 were aged between 6 weeks and 12 months. Three neonates and two babies under 4 months were assessed by means of telemedicine. The survey patients were followed for up to 6 months and no case of a missed cardiac diagnosis was recorded.

\section{Operation of the telecardiology service}

Three DGHs used the telemedicine service for paediatric patients (both new and review) of all ages, while Gillingham hospital used the service only for neonates. The district paediatricians used the telemedicine resources in different ways. When obtaining neonatal advice, echocardiograms were prerecorded for transmission for 13 of 19 babies. The telemedicine service enabled five of 10 newborns with a birth weight under $1600 \mathrm{~g}$ to avoid ambulance transportation to and from London (at a saving of over $£ 1700$ per journey). For older infants and children, monthly or bi-monthly "virtual" outreach clinics were

Table 1 Unit costs for selected resource items (2005-06 prices)

\begin{tabular}{lc}
\hline Resource items & Cost (2005-06 prices) \\
\hline Neonatal cot days & \\
$\quad$ Ventilated intensive care (level 3 unit) & $£ 807$ \\
High dependency care (levels 2 or 3) & $£ 515$ \\
Special care (levels 2 or 3) & $£ 335$ \\
Intensive care (specialist unit) & $£ 1192$ \\
Paediatric ward bed days & \\
District general hospital & $£ 329$ \\
Specialist & $£ 737$ \\
Outpatient attendance (inclusive of consultant & \\
paediatrician's and specialist's time) & \\
Teleclinic & $£ 172$ \\
Outreach clinic & $£ 167$ \\
London clinic (specialist only) & $£ 145$ \\
Echocardiogram & \\
Teleclinic & $£ 21$ \\
Outreach clinic & $£ 34$ \\
London clinic & $£ 155$ \\
Ambulance transfer London (one-way) & $£ 1725$ \\
Telemedicine service (based on 12 months and 38 & $£ 227$ (mean per patient) \\
telereferrals) and covering the equipment, maintenance & \\
contract, rental of ISDN-6 lines, telephone calls and value & \\
added tax (VAT)) & \\
& \\
\hline
\end{tabular}


Table 2 Demographic and clinical characteristics of patients assessed by paediatric cardiology specialists over 15 months

\begin{tabular}{|c|c|c|c|}
\hline Characteristics & $\begin{array}{l}\text { Teleconsultation } \\
(\mathrm{n}=75)\end{array}$ & $\begin{array}{l}\text { Face-to-face } \\
\text { assessment } \\
\text { ( } n=191)\end{array}$ & p Value \\
\hline \multicolumn{4}{|l|}{ Gender } \\
\hline Male & $44(58.7 \%)$ & $105(55.0 \%)$ & $\chi_{1}^{2}=0.30$ \\
\hline Female & $31(41.3 \%)$ & $86(45.0 \%)$ & $p=0.585$ \\
\hline \multicolumn{4}{|l|}{ Age when seen by specialist } \\
\hline 1 day-5 weeks & $19(25.3 \%)$ & $23(12.0 \%)$ & \\
\hline 6 weeks-12 months & $18(24.0 \%)$ & $38(19.9 \%)$ & $\chi_{4}^{2}=11.18$ \\
\hline $1-4$ years & $18(24.0 \%)$ & $52(27.2 \%)$ & $p=0.025$ \\
\hline $5-8$ years & $7(9.3 \%)$ & $41(21.5 \%)$ & \\
\hline 9 years and over & $13(17.3 \%)$ & $37(19.4 \%)$ & \\
\hline \multicolumn{4}{|l|}{ Symptom urgency or presentation } \\
\hline \multicolumn{4}{|l|}{ Newborns or infants receiving neonatal care } \\
\hline Critical CHD suspected* & $2(2.7 \%)$ & $8(4.2 \%)$ & \\
\hline Non-critical CHD suspected & $9(12.0 \%)$ & $9(4.7 \%)$ & \\
\hline Other cardiovascular symptoms & $8(10.7 \%)$ & $6(3.1 \%)$ & \\
\hline Paediatric outpatients or inpatients & & & $\chi_{5}^{2}=16.57$ \\
\hline Moderate or severe symptoms & $4(5.3 \%)$ & $34(17.8 \%)$ & $p=0.005$ \\
\hline Mild symptoms & $6(8.0 \%)$ & $20(10.5 \%)$ & \\
\hline Asymptomatic & $46(61.3 \%)$ & $114(59.7 \%)$ & \\
\hline \multicolumn{4}{|l|}{ Outcome of specialist assessment } \\
\hline \multicolumn{4}{|l|}{ Newborns or infants receiving neonatal care } \\
\hline Investigate urgently or within $24 \mathrm{~h}$ & $2(2.7 \%)$ & $14(7.3 \%)$ & \\
\hline $\begin{array}{l}\text { Transfer or re-admit to cardiac centre in } \\
\text { due course }\end{array}$ & $3(4.0 \%)$ & $6(3.1 \%)$ & \\
\hline Manage in DGH & $14(18.7 \%)$ & $3(1.6 \%)$ & $\chi_{6}^{2}=31.63$ \\
\hline Paediatric outpatients or inpatients & & & $\mathrm{p}<0.001$ \\
\hline Intervention urgent or scheduled & $2(2.7 \%)$ & $18(9.4 \%)$ & \\
\hline Investigation to be arranged & $4(5.3 \%)$ & $16(8.4 \%)$ & \\
\hline Review in cardiac clinic & $26(34.6 \%)$ & $59(30.9 \%)$ & \\
\hline Discharge from cardiac care: normal heart & $24(32.0 \%)$ & $75(39.3 \%)$ & \\
\hline
\end{tabular}

${ }^{*}$ Critical CHD defects at diagnosis were coarctation of aorta and transposition of the great arteries (three cases each), interrupted aortic arch, critical pulmonary stenosis, hypoplastic left heart syndrome and totally anomalous pulmonary venous connections (one case each).

$\mathrm{CHD}$, congenital heart disease; DGH, district general hospital.

Table 3 Diagnoses of infants and children for whom interventions were undertaken immediately or planned during the specialist consultations

\begin{tabular}{|c|c|c|c|c|}
\hline \multirow[b]{2}{*}{ Diagnosis } & \multicolumn{4}{|c|}{ Age when assessed } \\
\hline & $\begin{array}{l}\text { Birth to } \\
5 \text { weeks* }\end{array}$ & $\begin{array}{l}6 \text { weeks- } \\
6 \text { months }\end{array}$ & 7-12 months & $1-13$ years \\
\hline \multicolumn{5}{|l|}{ For surgical repair } \\
\hline Atrioventricular septal defect & 2 (1 TM) & - & - & - \\
\hline Coarctation of aorta & 3 & - & 1 & - \\
\hline Common arterial trunk with VSD & - & 1 (TM) & - & - \\
\hline Cor triatriatum and $A S D$ & - & - & - & 1 (13 years) \\
\hline Doubly committed subarterial VSD & 1 & - & - & - \\
\hline Hypoplastic left heart syndrome $\dagger$ & 1 & - & - & - \\
\hline Interrupted aortic arch and VSD & 1 & - & - & - \\
\hline $\begin{array}{l}\text { Secundum ASD (unsuitable for } \\
\text { transcatheter device closure) }\end{array}$ & - & - & - & 1 (4 years) \\
\hline Tetralogy of Fallot & - & 3 & 2 & - \\
\hline TAPVC & 1 & 1 & - & - \\
\hline Transposition of the great arteries & 3 (1 TM) & - & - & - \\
\hline VSD & - & 1 & - & - \\
\hline \multicolumn{5}{|l|}{ For transcatheter intervention } \\
\hline Pulmonary valvar stenosis & 2 & 1 & 2 & 1 (1.5 years) \\
\hline Secundum ASD & - & - & - & 2 (1.7 and 3 years) \\
\hline Patent arterial duct & 1 (TM) & 1 (TM) & 1 & 1 (9 years) \\
\hline
\end{tabular}

*Babies born in the district hospitals; tfinal outcome was non-surgical with "comfort" care.

ASD, atrial septal defect; TAPVC, totally anomalous pulmonary venous connections; TM, telemedicine assessment;

VSD, ventricular septal defect. 
held at two DGHs with four to six patients and their parents present, and the paediatricians either performed echocardiograms in real time or transmitted pre-recorded videos. Chest $x$ ray films and resting electrocardiogram (ECG) tracings could be displayed using object camera visualisers; during 32 Basildon paediatric teleconsultations, ECG tracings were displayed for 27 patients and $x$ ray images for 22 patients. The electronic stethoscopes were used on 11 occasions: six with real-time echocardiography and five when pre-recorded videos were transmitted. In the third hospital, during the teleconferences pre-recorded echocardiograms were transmitted in the absence of patients, with seven cases discussed on average.

The mean time per teleconsultation for the 19 neonates was 21.1 (SD 5.5) min. For the "virtual" outpatients, the means were 14.4 (SD 3.9) min for 26 consultations involving real-time echocardiograms, and 13.3 (SD 3.4) min for 16 consultations with prerecorded echocardiogram transmissions. In the hospital where pre-recorded echocardiograms were discussed, the mean time spent was 8.5 (SD 1.7) min for 22 cases (including 10 review patients).

\section{Costs of referral services}

In our previous paper, the costs for neonates and older children were analysed separately with no statistically significant difference

Table 4 Bootstrapped mean NHS cost per new patient for all four hospitals, for three hospitals providing level 2 neonatal care and for Basildon hospital alone (2005-06 prices)

\begin{tabular}{|c|c|c|c|}
\hline Four hospitals & $\begin{array}{l}\text { Teleconsultation, } \\
n=65\end{array}$ & $\begin{array}{l}\text { Conventional } \\
\text { referral, } n=191\end{array}$ & $\begin{array}{l}p \text { Value } \\
\text { (t test) }\end{array}$ \\
\hline \multicolumn{4}{|l|}{ Initial consultation day } \\
\hline Mean (SD) & f839 (£573) & f587 (f1369) & 0.164 \\
\hline $95 \% \mathrm{Cl}$ & f717 to $f 999$ & f431 to $f 843$ & \\
\hline \multicolumn{4}{|l|}{14 days } \\
\hline Mean (SD) & £2978 (£5830) & f1846 (f5308) & 0.163 \\
\hline $95 \% \mathrm{Cl}$ & f1781 to $f 4703$ & $\mathrm{f} 1239$ to $f 2798$ & \\
\hline \multicolumn{4}{|l|}{6 months } \\
\hline Mean (SD) & f6337 (£15 149) & $£ 4294$ (£10 770) & 0.253 \\
\hline $95 \% \mathrm{Cl}$ & $\mathrm{f} 3313$ to $\mathrm{f} 11011$ & $\mathrm{f} 3045$ to $\mathrm{f} 6175$ & \\
\hline $\begin{array}{l}\text { Three hospitals with level } 2 \\
\text { neonatal units and 3- or 4- } \\
\text { monthly outreach clinics }\end{array}$ & $\begin{array}{l}\text { Teleconsultation, } \\
\mathrm{n}=56\end{array}$ & $\begin{array}{l}\text { Conventional } \\
\text { referral, } n=129\end{array}$ & \\
\hline \multicolumn{4}{|l|}{ Initial consultation day } \\
\hline Mean (SD) & f673 (£336) & £507 (£989) & 0.227 \\
\hline $95 \% \mathrm{Cl}$ & $f 588$ to $f 763$ & $f 374$ to $£ 735$ & \\
\hline \multicolumn{4}{|l|}{14 days } \\
\hline Mean (SD) & £1519 (£3157) & f1724 (£4983) & 0.775 \\
\hline $95 \% \mathrm{Cl}$ & $\mathrm{f} 930$ to $£ 2750$ & f1055 to $f 2930$ & \\
\hline \multicolumn{4}{|l|}{6 months } \\
\hline Mean (SD) & $£ 2772$ (£7097) & £4334 (£11 308) & 0.352 \\
\hline $95 \% \mathrm{Cl}$ & f1457 to $f 5670$ & f2794 to $f 6924$ & \\
\hline $\begin{array}{l}\text { Basildon hospital over } \\
12 \text { months }\end{array}$ & $\begin{array}{l}\text { Teleconsultation, } \\
\mathbf{n}=\mathbf{3 8}\end{array}$ & $\begin{array}{l}\text { Conventional } \\
\text { referral, } n=39\end{array}$ & \\
\hline \multicolumn{4}{|l|}{ Initial consultation day } \\
\hline Mean (SD) & $£ 515$ (£243) & $£ 320(£ 517)$ & 0.041 \\
\hline $95 \% \mathrm{Cl}$ & $\mathrm{f} 460$ to $\mathrm{f} 641$ & $f 202$ to $f 590$ & \\
\hline \multicolumn{4}{|l|}{14 days } \\
\hline Mean (SD) & f1054 (£2243) & f1018 (£4665) & 0.966 \\
\hline $95 \% \mathrm{Cl}$ & f548 to $£ 2277$ & $£ 211$ to $£ 4368$ & \\
\hline \multicolumn{4}{|l|}{6 months } \\
\hline Mean (SD) & £1756 (£3875) & f2861 (f7525) & 0.426 \\
\hline $95 \% \mathrm{Cl}$ & $f 873$ to $£ 3791$ & f1075 to $f 6241$ & \\
\hline
\end{tabular}

Statistical tests were performed on non-bootstrapped mean costs. $\mathrm{Cl}$, confidence interval; SD, standard deviation. found in the mean NHS costs after 6 months for the alternative referral strategies. ${ }^{16}$ For this paper, patient costs for newborns and older children were analysed jointly for three scenarios: all four hospitals; three hospitals with level 2 neonatal units and outreach clinics held 3- to 4-monthly; and Basildon Hospital only where the telemedicine service was used over 12 months. Table 4 shows that the initial consultation day for telemedicine patients was more costly, with the difference in Basildon being statistically significant ( $£ 515$ vs $£ 320 ; p=0.041$ ). The difference relates to the cost of the telemedicine service itself with mean costs per patient ranging from $£ 227$ in Basildon (38 patients) to £892 in Gillingham (nine patients). Teleconferencing continued to be more costly, although not significantly, across the four hospitals after 14 days and 6 months. However, in the scenarios involving the DGHs with level 2 units and in Basildon alone, telecardiology became cost neutral.

\section{DISCUSSION}

The paediatric departments in the DGHs were invited to join the study because they had a consultant member of staff with expertise in echocardiography who assisted during the outreach clinic sessions. Further tuition was provided when the telemedicine service commenced. Consequently, the district paediatricians who undertook the teleconferences did not rely on the remote specialists to direct the imaging of the hearts. The chest $x$ rays and ECGs were always transmitted in a clear and diagnostic format and the electronic stethoscopes allowed the specialists to clearly hear heart sounds and murmurs. The advantage of each item was that it provided a check on the diagnosis provided by echocardiography. In every case, the $x$ ray, ECG and audible sounds were compatible with the specific diagnosis derived from the echocardiography, which was reassuring for the cardiologists. Unfortunately, however, for technical reasons the electronic stethoscopes were only used for 11 children.

By holding monthly teleconferences over the survey period in addition to the quarterly outreach clinics, the paediatricians in two hospitals almost doubled the number of new patients assessed by specialists. In the neonatal units, doctors relied on the technology when they were uncertain about the diagnosis of a heart problem or the continued management of a baby who was failing to thrive, thus avoiding the transfer of small newborns. In $\mathrm{RBH}$, three consultant paediatric cardiologists and two specialist registrars undertook the teleconsultations according to their availability.

A separately reported survey of the children's parents showed that they considered teleconsultations to be acceptable for obtaining specialist advice. They perceived that the availability of a telemedicine service would reduce waiting times for new appointments for asymptomatic children who normally were seen in an outreach clinic. For symptomatic patients, the service minimised the need for children to travel to London. ${ }^{20}$ As both the outreach clinics and the teleconferences were held in the DGHs, there was no parental cost advantage associated with the alternative referral methods. ${ }^{16}$

The key cost components for the telemedicine service were the equipment packages, the ISDN line rental and call charges. The expected lifetime of the equipment was 5 years, ${ }^{19}$ so the mean patient cost for each hospital was based on the first year of the equipment's use plus the ISDN charges for the same period. ${ }^{16}$ Sharing the equipment with other users was advantageous. In Gillingham, the telecardiology service was also used for fetal heart screening and 52 pregnant women were assessed. So the actual mean cost specifically for the service in the first year (for 61 patients) was $£ 132$ per patient, as opposed to £892 for each neonate. However, the importance of this evaluation was the adoption of a longer term perspective for assessing the 


\section{What is already known on this topic}

- Telecardiology services in Northern Ireland and Scotland are used for triaging newborns with heart symptoms in district hospitals for transfer to paediatric cardiology centres.

- Paediatric cardiology outpatient services are coping with increasing workloads of children referred with asymptomatic heart murmurs for echocardiographic screening.

cost of hospital care. The telecardiology referral service was cost neutral over 6 months when compared with conventional referral arrangements, particularly within the hospitals with level 2 neonatal units and infrequent outreach clinics.

The telemedicine equipment was retained by the hospitals and the patterns of use established during the evaluation have continued to date. In the second year, 132 outpatients were assessed remotely and there were 23 emergency telereferrals of babies and children. The policy of relying on the judgement of the referring clinicians in selecting cases for teleconferences has not been revised and probably contributed to the sustainability of the service. The video conferencing equipment is still functioning reliably and the quality of the images and sounds transmitted via the ISDN-6 lines has improved over the years. In Colchester, the telemedicine resources are also used regularly by regional cancer networks.

The 15 paediatric cardiology centres in the UK have well established outreach services providing continuity of care for increasing numbers of children with CHD. How can these centres, with their small cadres of specialists, extend their services to cope with ever expanding flows from DGHs of newly referred patients with suspected anomalies? Innovative use of telemedicine services alongside conventional outreach services should suitably enhance access. However, a limiting factor in the expansion of telecardiology networks could quickly emerge if the paediatric cardiologists, who currently travel to numerous hospitals, are expected to take on telecardiology without job plan rationalisation. This issue might best be addressed by training paediatricians to become proficient in echocardiography ${ }^{21}$ Each DGH should be encouraged to identify a paediatrician willing to be trained to undertake much of the routine screening for $\mathrm{CHD}$, with clear protocols over when to refer to the tertiary centre. Back up would continue to be given by the tertiary centre through outreach clinics and teleconferencing sessions (involving both live and pre-recorded images). This should also include the remote triage of sick neonates, many of whom have been born prematurely with immature heart problems, such as a failure of the arterial duct to close or persistent pulmonary hypertension, and who usually do not require tertiary cardiac transfer. Re-configuring paediatric cardiac care along these lines would be consistent with stated NHS policy of having local services that minimise the psychological and financial stress on patients and their families. ${ }^{22}$

In conclusion, this evaluation has shown that, from an NHS perspective, the provision of telecardiology for children is a cost neutral service and that if combined with other telemedicine or administrative uses, it is likely to be financially beneficial. This study has therefore demonstrated an important role for telecardiology in an increasingly burdensome area of health care.

Acknowledgements: We thank the staff in the district hospitals in Basildon, Colchester, Southend and Gillingham, and the Royal Brompton Hospital for participating in this study.

Funding: The Department of Health and the Charitable Funds Committee of the Royal Brompton and Harefield NHS Trust funded the project.

\section{What this study adds}

- Echocardiograms for children, performed by paediatricians live or as pre-recorded videos, can be reliably transferred for diagnostic assessment during teleconsultations with specialists.

- Telecardiology networks that complement existing outreach services in district hospitals can economically facilitate greater access to paediatric cardiologists while keeping their services local.

Competing interests: None.

Ethics approval: Multi-centre and local research ethics committees approved this project.

Disclaimer: The Health Economics Research Group at Brunel University receives funding from the Department of Health Policy Research Programme. The views expressed in the publication are those of the authors and not necessarily those of the Department of Health.

\section{REFERENCES}

1. Karuppaswamy V, Kelsall, W. Review of paediatric cardiology services in district general hospitals. Arch Dis Child 2006;91(Suppl 1):A59-A60.

2. Maynard L, Franklin RCG, Wray J. A survey of professionals delivering secondary care regarding their requirements for paediatric cardiac services as provided by specialists. Cardiol Young 2005;15:489-92.

3. Murugan SJ, Thomson J, Parsons JM, et al. New outpatient referrals to a tertiary paediatric cardiac centre: evidence of increasing workload and evolving patterns of referral. Cardiol Young 2005;15:43-6.

4. Wagstaff MH, Rigby ML, Redington AN. Increasing workload and changing referral patterns in paediatric cardiology outreach clinics: implications for consultant staffing. Heart 1998:79:223-4.

5. Belmont JM, Mattioli LF, Goertz KK, et al. Evaluation of remote stethoscopy for pediatric telecardiology. Telemed J 1995;1:133-49.

6. Casey F, Brown D, Craig BG, et al. Diagnosis of neonatal congenital heart defects by remote consultation using a low-cost telemedicine link. J Telemed Telecare 1996;2:165-9.

7. Cloutier A, Finley J. Telepediatric cardiology practice in Canada. Telemed J E Health 2004;10:33-7.

8. Finley JP, Sharratt GP, Nanton MA, et al. Paediatric echocardiography by telemedicine - nine years' experience. J Telemed Telecare 1997:3:200-4.

9. Bellavance M, Béland MJ, van Doesburg NH, et al. Implanting telehealth network for paediatric cardiology: learning from the Quebec experience. Cardiol Young 2004;14:608-14.

10. Casey F, Brown D, Corrigan N, et al. Value of a low-cost telemedicine link in the remote echocardiographic diagnosis of congenital heart defects. J Telemed Telecare 1998;4(Suppl 1):46-8.

11. Mulholland HC, Casey F, Brown D, et al. Application of a low cost telemedicine link to the diagnosis of neonatal congenital heart defects by remote consultation. Heart 1999;82:217-21.

12. Grant B, Wallace JG, Hobson RA, et al. Telemedicine applications for the regional paediatric cardiology service in Northern Ireland. J Telemed Telecare 2002;8(Suppl 2):31-3.

13. Archer H. Scottish paediatric telemedicine project: final report. Glasgow: Yorkhill Hospital, 2006. Available from http://www.show.scot.nhs.uk/publications/ publications/Telemed\%20Report.pdf (accessed 15 December 2008).

14. Kotis T. Telecommunications model for continuing education of health professionals: the Royal Brompton case. Stud Health Technol Inform 2003;92:127-31.

15. Tsilimigaki A, Maraka S, Tsekoura T, et al. Eighteen months' experience with remote diagnosis, management and education in congenital heart disease. J Telemed Telecare 2001;7:239-43.

16. Dowie R, Mistry H, Young TA, et al. Telemedicine in pediatric and perinatal cardiology: economic evaluation of a service in English hospitals. Int J Technol Assess Health Care 2007;23:116-25.

17. Curtis L, Netten A. Pay and prices index. Unit costs of health and social care 2006 Canterbury, UK: Personal Social Services Research Unit, University of Kent at Canterbury.

18. Manly BFJ. Randomisation, bootstrap and Monte Carlo methods in biology. 2nd edn Texts in Statistical Science. London: Chapman \& Hall, 1997.

19. Jacklin PB, Roberts JA, Wallace P, et al. Virtual outreach: economic evaluation of joint teleconsultations for patients referred by their general practitioner for a specialist opinion. BMJ 2003;327:84-8.

20. Weatherburn G, Dowie R, Mistry $\mathrm{H}$, et al. An assessment of parental satisfaction with mode of delivery of specialist advice for paediatric cardiology: face-to-face versus videoconference. J Telemed Telecare 2006;12(Suppl 1):57-9.

21. Pushparajah K, Garvie D, Hickey A, et al. Managed Care Network for the assessment of cardiac problems in children in a district general hospital: a working model. Arch Dis Child 2006;91;892-5.

22. Department of Health. Report of the Paediatric and Congenital Cardiac Services Review Group. London: DOH, 2003. Available from http://www.advisorybodies.doh. gov.uk/childcardiac/pccsreptdec03.pdf (accessed 15 December 2008) 